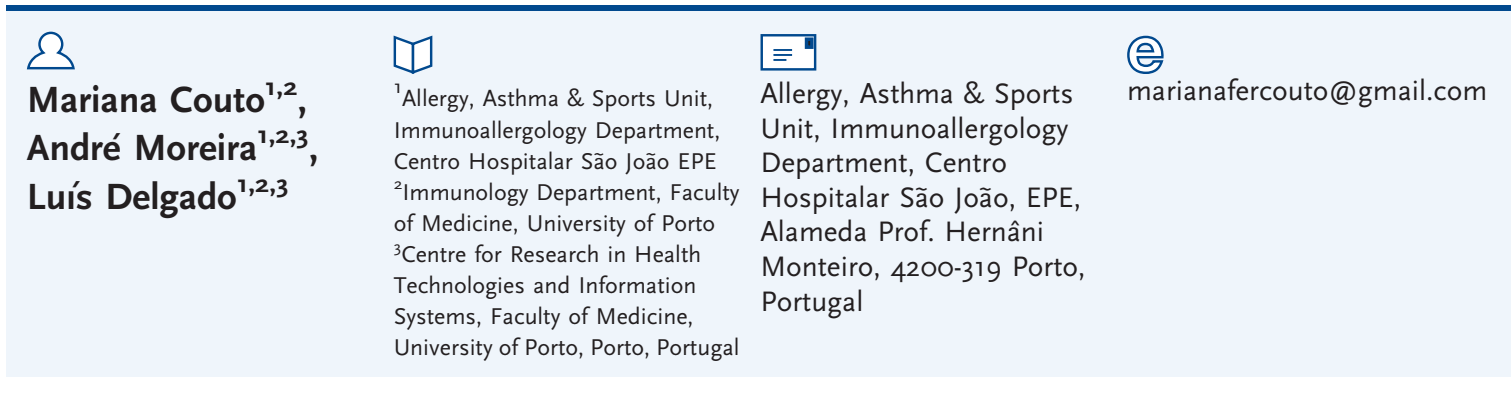

\title{
Diagnosis and treatment of asthma in athletes
}

\section{Educational aims}

$\odot$ To increase awareness in physicians for a prevalent but manageable health problem among athletes.

$\odot$ To describe the strategies to diagnose asthma in athletes and the most common differential diagnoses.

○ To improve physicians' confidence in dealing with international guidelines and treating these patients.
Statement of interest

A. Moreira has received fees for providing unrestricted educational training on asthma to general practioners and takes part on the scientific advisory board of Danone-Portugal.
Regular physical activity is recommended for all individuals, but asthmatic athletes face special challenges in managing their disorder while practicing sport. In athletes, a diagnosis of asthma is crucial because of potential implications not only on their general health, but also on their competing performance. However, it is often challenging due to heterogeneity in asthma expression [1], as well as variability in clinical, physiological and pathologic parameters [2]. In addition, multiple asthma phenotypes exhibiting differences in clinical response to treatment exist, which poses additional difficulties in the management of these patients [3]. Also, careful consideration of available therapies is required in order to avoid adverse effects on athletic performance and also to comply with World Anti-Doping Agency (WADA) regulations.

Therefore, athlete's asthma often perplexes, frustrates and distresses both patients and their physicians [4]. In this context, and with the 2012 Olympic Games approaching, it seemed appropriate to review some answers to the most frequently asked questions regarding the diagnosis and treatment of this condition. Our aim is to demystify, in an educational perspective, this subject, and improve the physician's confidence in dealing with these patients.

\section{What is exercise-induced asthma?}

Well known by Aretaeus since the year 100 AD [5], asthma induced by sport is not always easy to describe and recognise. For this reason, in 2008, the joint Task Force of the European Respiratory Society and the European Academy of Allergy and Clinical Immunology, in cooperation with $\mathrm{GA}^{2} \mathrm{LEN}$, defined exercise-induced asthma (EIA) as exercise-induced symptoms and signs of
HERMES syllabus link: B.1.1 
asthma occurring after intensive physical exercise [6]. The reduction in lung function (forced expiratory volume in 1 second; FEV 1 ) occurring after a standardised exercise test is called exercise-induced bronchoconstriction (EIB).

Atopy and the type of sport have been identified as major risk factors for asthma in athletes [4]. In this perspective, two different clinical phenotypes of asthma in athletes have been recently suggested by HAAHTELA et al. [7]: 1) those who have had asthma from early childhood, often accompanied by allergic sensitisation; and 2) another distinct phenotype with onset of symptoms during the sporting career, through repeated heavy training and competitions, presenting with bronchial responsiveness to a eucapnic hyperventilation test and a variable association with atopic markers and eosinophilic airway inflammation.

\section{Why screen athletes for EIA/EIB?}

In athletes, asthma diagnosis is particularly relevant because of potential implications on competition performance and training, as airway narrowing during exercise could compromise ventilatory capacity and efficiency. Moreover, asthma is definitely the most common chronic medical condition among Olympic athletes [8]. It is also well known that it is more frequent than in the general population, as well as more prevalent in elite athletes (particularly those who participate in endurance events, swimming and winter sports) than in recreational athletes $[4,6]$.

Additionally, asthma has been highlighted as a significant risk factor for unexplained death in young and healthy subjects [9], and a high proportion of asthma-related deaths have been reported in athletes associated with a sporting event [10]. Moreover, there is a subgroup of athletes who are asymptomatic but present with objective evidence of EIB [11], which raises the question of its potential under diagnosis and the resulting under performance.

Furthermore, and as occurs for all asthmatic subjects, this untreated condition results in chronic sustained inflammation associated with persistent epithelial damage, which contributes to airway remodelling and fibrotic changes, progressive lung function decline over time and fixed obstruction [12].
So, bearing in mind that care should be taken to ensure that sport does not affect the health or welfare of the participants, as stated by the International Olympic Committee (IOC) Medical Commission, it is easy to understand the imperative focus that should be posed in the diagnosis of asthma.

\section{How to diagnose EIA}

The clinical presentation of EIA includes wheezing, cough, shortness of breath and/or chest tightness, generally occurring within 5 to $30 \mathrm{~min}$ after intense exercise (and sometimes during) [1, 11]. Gradual spontaneous improvement is common after finishing exercise. Physical examination can often reveal expiratory dyspnoea, expiratory wheezing or rhonchi and other signs of bronchial obstruction, such as respiratory retractions $[6,13]$.

A variety of symptoms and signs associated with allergic rhinitis can be part of the clinical presentation as allergic rhinitis affects a high percentage of elite competitive athletes. A significant increased prevalence of hayfever has been observed when compared with the general population, and is highest among endurance athletes. Therefore, sneezing, anterior rhinorrhoea and bilateral nasal obstruction, as well as ocular symptoms such as teary, burning and itching eyes, should be addressed [14]. Other symptoms include significant loss of smell (hyposmia or anosmia), snoring, postnasal drip or chronic cough, and itching ears, nose and throat. Besides, physicians should be aware of the fact that in athletes the clinical presentation of rhinitis is frequently more subtle and might include poor-quality sleep, fatigue, reduced exercise performance and difficulty to recover after more demanding exercise sessions [14].

But it should be noted that in athletes symptoms have been shown to be poor predictors of asthma [15]. Asthma-like symptoms in elite athletes are not necessarily associated with classic features of asthma. Athletes may not suffer from the obvious symptoms like regular asthmatic patients do, but rather suffer from cough [15] or some nonspecific complaints, such as poor performance or "feeling out of shape", abdominal pain, headaches, muscle cramps, fatigue and dizziness [16].

In the specific case of competitive athletes, this poses several issues unique to this population for diagnosing EIA/EIB. Heavy 
training with the extremely high level of physical fitness and maximum oxygen uptake reached makes it difficult to discriminate between physiological and pathological limitations to maximum exercise [6]. Moreover, some athletes will not reveal their symptoms due to fear that their asthma disclosure will be detrimental, whereas, on the other side, athletes without asthma may try to secure asthma treatments in an attempt to gain a competitive advantage [1], although several studies have proved that anti-asthmatic drugs do not enhance performance in healthy subjects [17] this is still a general misbelief. Therefore, objective evidence of asthma should always be part of the assessment in these subjects.

However, the answer to this question is not that simple. Baseline spirometry is poorly predictive of asthma in competitive athletes. Often they record lung function values higher than the general population; they may appear to be within the "normal" range, although, in reality, show a pulmonary deficit on the basis of what is expected for an athlete [4, 18].

\section{Which diagnostic procedures should then be performed and how should we interpret them?}

Due to the heterogeneity in asthma expression, the assessment of asthma should be multidimensional including variability in clinical, physiological and pathological parameters. Also, and in relation to the the above mentioned facts related to clinical presentation and symptoms in athletes, it is recommended in this special population to obtain objective evidence to validate an asthma diagnosis by either a positive bronchodilator or bronchoprovocation test. Diagnostic tests and positivity criteria are presented in table 1. Therefore, its evaluation requires a combination of patient's history, clinical examination and judgment, as well as adequate tests in a stepwise approach [6].

Detailed information about past or current atopic disorders should be addressed and skin-prick tests or specific immunoglobulin E (in case skin-prick tests could not be performed) should also be carried out in order to assess for atopy.

Important information to be investigated when evaluating an athlete with suspected asthma include: previous appointments with their physician; parental history of asthma; hospital emergency department visits or admissions for acute asthma exacerbations or oral corticosteroids treatment; detailed description of both daytime and night-time symptoms; triggering factors; and medication.

A special consideration should be made regarding cases of athletes with known asthma but who, due to a well-controlled status, record a negative result in the bronchial provocation test(s). In this case, the negative result should not be interpreted as a misdiagnosis but as an improvement in relation to a well-designed therapeutic strategy.

\section{Which are the differential diagnoses?}

Other clinical entities can produce symptoms similar to those related to asthma $[19,20]$ and might, therefore, lead to an incorrect diagnosis and unsuccessful treatments (table 2). Exercise-induced dyspnoea, in particular, is associated with many disease processes and it is interesting to note that it is in fact an uncommon complaint among those who suffer from EIB [19]. Wheezing or stridor can also be caused by other airway abnormalities and closely mimic EIB.

A few more difficulties arise from this question. In one instance, most of the elite athletes referred for respiratory problems do not suffer from asthma or EIB [21]. Also, it is important to bear in mind that more than one condition may coexist in a given subject. Furthermore, in the particular case of athletes, their underlying high cardiorespiratory fitness makes the diagnostic process even more complex, as a variety of both common and rare alternative diagnoses must be considered $[6,13]$.

One of the most frequent differential diagnoses is exercise-induced inspiratory stridor or vocal cord dysfunction. Obstruction of the upper airway can cause symptoms such as shortness of breath, increased inspiratory effort, stridor and wheeze, and in many subjects it is only presented during exercise [19]. Symptoms are thought to occur due to the relatively small cross-sectional area of the laryngeal orifice, which may be even further reduced by the negative pressure created on inspiration during heavy exercise, and the paradoxical movement (adduction instead of 
Table 1 Diagnosis methods and positivity criteria set by the International Olympic Committee to document exercise-induced bronchoconstriction in athletes [1, 4, 6]

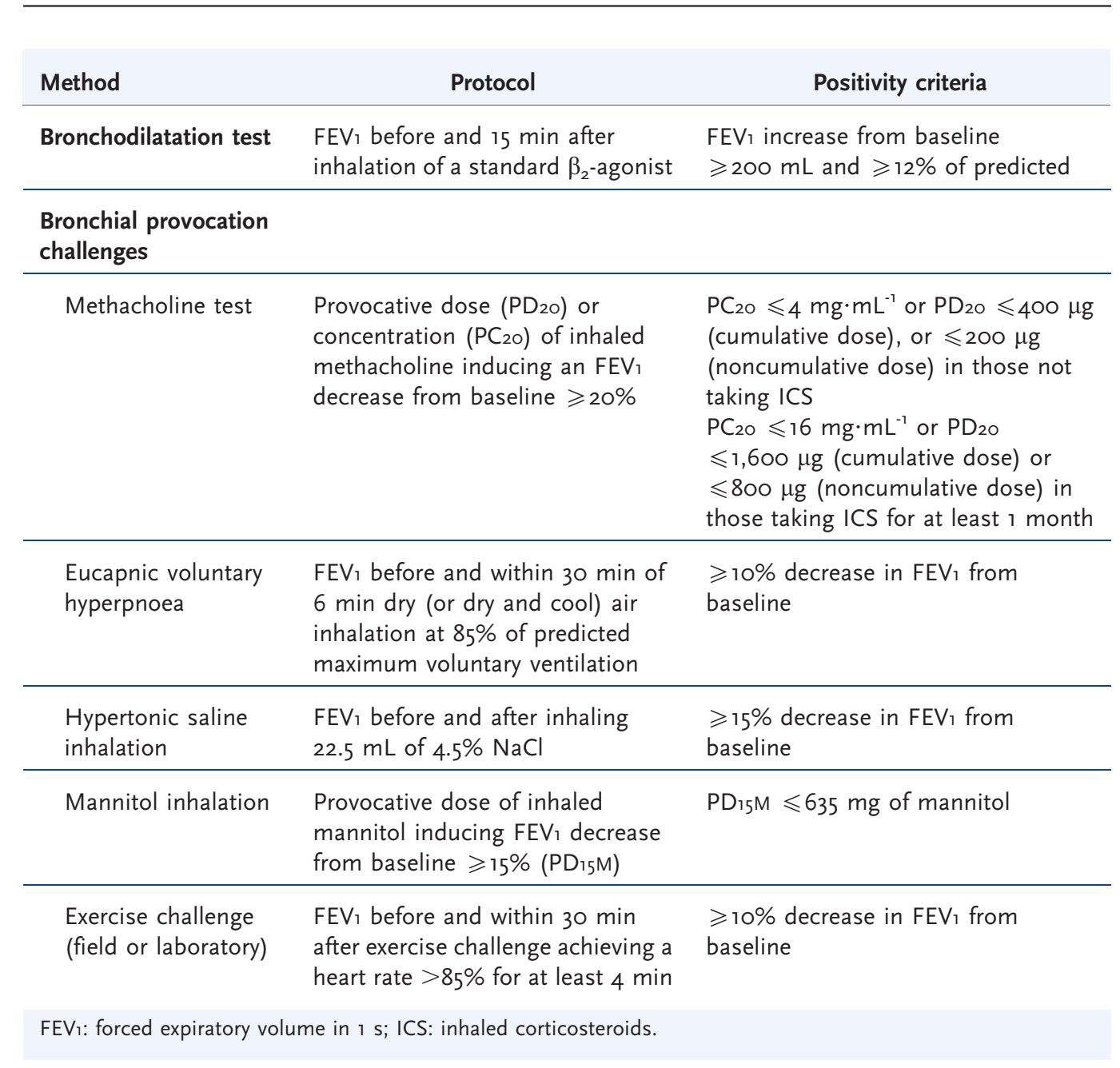

normal abduction) of the vocal cords during inspiration $[6,19]$. This condition is frequently associated with psychologically stressful events such as competitions. Its prevalence has been reported to be higher in elite athletes than in the general population, and it affects $5 \%$ of those referred for routine evaluation for asthma and/or EIB [22]. Differential diagnosis is important as asthma treatment will have definitively no effect. However, it should be noticed that about half of athletes can present with concomitant EIB [22].

Besides vocal cord dysfunction, exertional inspiratory stridor may be caused by foreign body aspiration, poor-performance, psychogenic stridor, infectious croup, laryngomalacia, subglottic stenosis and exercise-induced anaphylaxis, although these diagnoses are much more infrequent.
Upper respiratory tract infections are also very common in elite athletes, giving rise to respiratory complaints over prolonged periods of time that are often related to competition seasons or heavy training blocks [23].

Another differential diagnosis relates to poor physical fitness. The increase in respiratory drive and work may be interpreted as pathologic by subjects who find that it limits their ability to perform to their expectations [19]. Deconditioned subjects have a lower lactate/ventilatory threshold, accumulating lactate and increasing minute ventilation with lesser amounts of exercise; excess lactate build-up results in exercise-associated increases in ventilation and ultimately hypocapnia. An athlete who has become deconditioned during the "off season" may interpret an increase in respiratory drive with lesser 


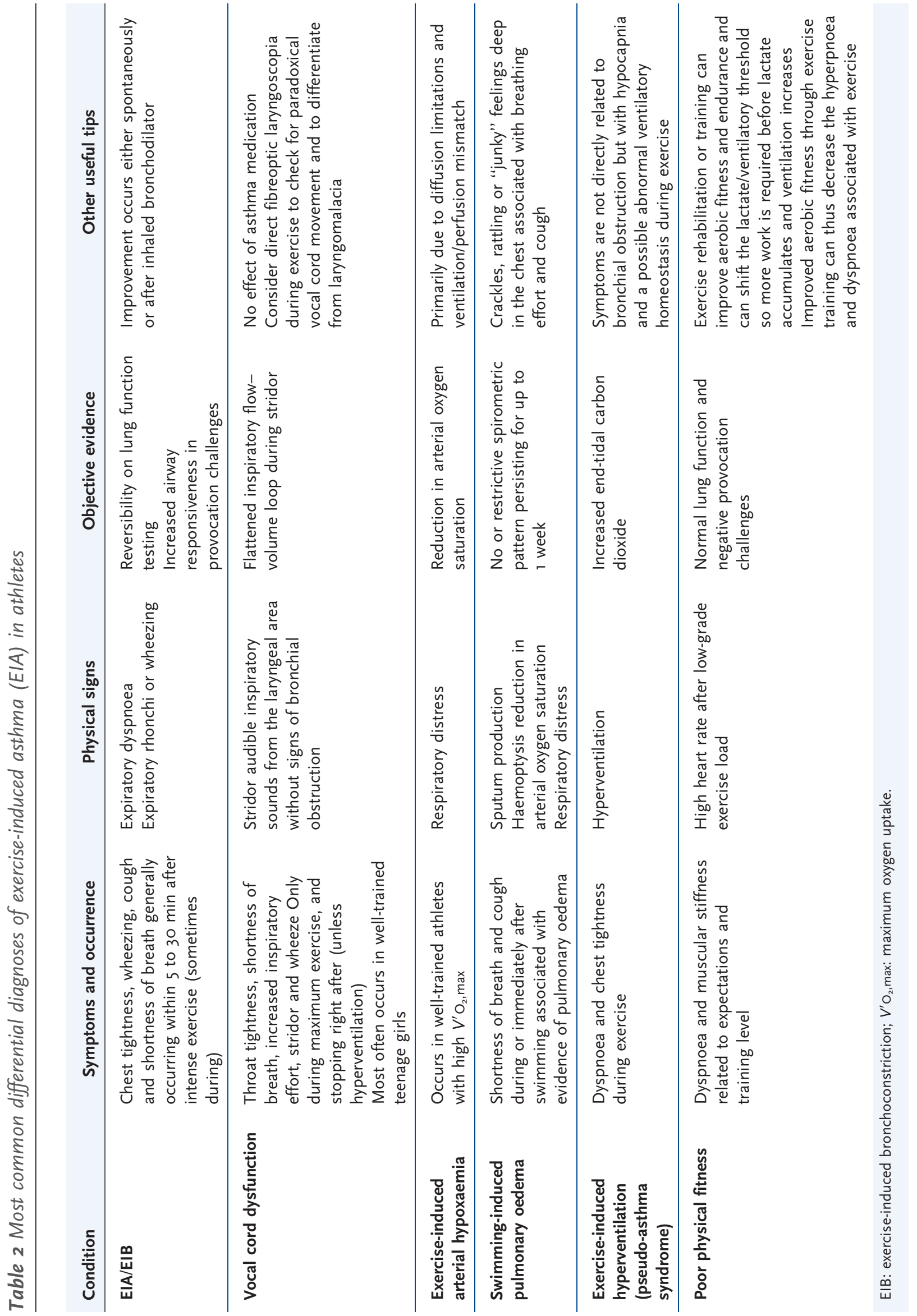


amounts of exercise as pathologic or as asthma [19].

Other chronic disorders that are possible differential diagnoses related to asthma in athletes are presented in table 2. Heart diseases and other respiratory disorders should also be considered. Obesity, which may represent a differential diagnosis to EIA in the common asthmatic patient, is rare in athletes.

\section{How to treat asthma in athletes}

Optimal asthma treatment aims to control both symptoms and inflammation, with minimal or absent adverse effects of the medication, allowing full participation in physical activity and sporting activities.

There is no evidence supporting different treatment for EIA/EIB in athletes and nonathletes. However, when choosing treatment for a specific athletic population compared with the common asthmatic patient, some additional factors should be taken into account. For the top athlete it is important not only to control symptoms of asthma and prevent progression, but it becomes equally imperative to reduce its impact on sporting performance, often practiced under extraordinary circumstances. Therefore, the possibility of a side-effect (e.g. systemic effects of inhaled treatments or sedation of some $\mathrm{H}_{1}$ antihistamines) from a prescribed treatment should also be carefully considered [17].

Several types of drug combinations are frequently needed to fully control EIA/EIB in athletes, and comprise two categories: controller (anti-inflammatory) and reliever (premedication before exercise and treatment of symptoms) medication (table 3). The same principles for asthma management in the general population are applicable to athletes [26], including a "step-up" approach if worsening of EIA symptoms occur, as it may be a sign of inadequate control of underlying asthma [4].

When only intermittent symptoms are present, as-needed reliever medication is suitable. Short-acting $\beta_{2}$-agonists, such as salbutamol or terbutaline, are effective in reversing EIA/EIB. Their efficacy is optimal approximately $20 \mathrm{~min}$ after inhalation and wanes within a few hours. Therefore, they are also used before exercise for prevention. Shortacting $\beta_{2}$-agonists are more commonly used, but long-acting $\beta_{2}$-agonists are also effective as a prevention strategy as they protect for up to $12 \mathrm{~h}$ after a single inhalation. However, only formoterol acts as fast as short-acting $\beta_{2}$-agonists. Therefore, formoterol or a shortacting $\beta_{2}$-agonist, but not salmeterol, should be chosen to reverse EIA/EIB.

Nevertheless, it is important to note that there may be potential adverse events with the use of these agents, and healthcare providers should be aware of these concerns [1]. Inhaled $\beta_{2}$-agonists may mask worsening airway inflammation. Also, EIB is frequently not completely abolished, as exemplified in study with a maximum reduction in $\mathrm{FEV}_{1}$ post-exercise of 18-19\% after inhaling salmeterol compared with $30 \%$ after placebo [27]. In addition, tachyphylaxis occurs with regular use of inhaled $\beta_{2}$-agonists, reducing their protective effect $[1,17]$. Additionally, some concerns regarding cardiovascular side-effects in patients who uptake long-acting inhaled $\beta_{2}$ agonists on a regular basis have been highlighted [28, 29]. Despite some controversy and the lack of large, well-designed, controlled, prospective studies evaluating these risks, while this question remains unresolved this possibility should be taken into consideration when treating athletes and other patients with inhaled $\beta_{2}$-agonists $[30,31]$. Furthermore, an increased risk of serious adverse events with regular salmeterol has recently been shown, together with an increase in risk of asthmarelated mortality in patients not using inhaled corticosteroids [32]. Besides, it has been proposed that airway inflammation could potentiate downregulation of bronchoprotection in response to $\beta_{2}$-agonists [33]. Therefore, long-acting $\beta_{2}$-agonists should never be used regularly without an inhaled steroid, and so should be reserved for a further step-up [26].

When bronchodilation is needed, inhaled ipratropium bromide may also be tried before exercise or competition; it has been suggested that endurance athletes respond particularly well and with a higher reversibility to this drug than to inhaled $\beta_{2}$-agonists [13] (unpublished data).

Controller medication with inhaled corticosteroids should be started if symptoms persist, if bronchial hyperesponsiveness and inflammation are present, or if bronchodilation therapy is required on a regular basis. Due to tachyphylaxis associated with inhaled $\beta_{2^{-}}$ agonists, the use of controller medication will avoid their daily use, optimising their rescue or preventive effects when most needed. 
Table 3 Most frequent asthma and rhinitis medications and the 2012 World Anti-Doping Agency (WADA) rules [24]

\begin{tabular}{|c|c|c|}
\hline Treatment & WADA rules & Notes \\
\hline \multicolumn{3}{|l|}{ Controller medication } \\
\hline Inhaled corticosteroids & \multicolumn{2}{|l|}{ Permitted } \\
\hline Anti-leukotrienes & \multicolumn{2}{|l|}{ Permitted } \\
\hline Nasal corticosteroids & \multicolumn{2}{|l|}{ Permitted } \\
\hline Allergen immunotherapy & \multicolumn{2}{|l|}{ Permitted } \\
\hline \multicolumn{3}{|l|}{ Reliever medication } \\
\hline Inhaled $\beta_{2}$-agonists & $\begin{array}{l}\text { Prohibited except } \\
\text { salbutamol, formoterol } \\
\text { and salmeterol }\end{array}$ & $\begin{array}{l}\text { Salbutamol maximum } 1,600 \mu \mathrm{g} \text { over } \\
24 \mathrm{~h} \text { and formoterol maximum } 36 \mu \mathrm{g} \\
\text { over } 24 \mathrm{~h} \text {; the presence in urine of } \\
\text { salbutamol }>1,000 \mathrm{ng} \cdot \mathrm{mL}^{-1} \text { or } \\
\text { formoterol }>30 \mathrm{ng} \cdot \mathrm{mL}^{-1} \text { is presumed not } \\
\text { to be an intended therapeutic use of the } \\
\text { substance and will be considered as an } \\
\text { adverse analytical finding }\end{array}$ \\
\hline Oral $\beta_{2}$-agonists & \multicolumn{2}{|l|}{ Prohibited } \\
\hline Oral corticosteroids & Prohibited & $\begin{array}{l}\text { Therapeutic use exemption approval } \\
\text { required }\end{array}$ \\
\hline Antihistamines & Permitted & $\begin{array}{l}\text { Second-generation } \mathrm{H}_{1} \text {-antihistamines } \\
\text { should be preferred to avoid somnolence }\end{array}$ \\
\hline $\begin{array}{l}\text { Inhaled or nasal ipratropium } \\
\text { bromide }\end{array}$ & Permitted & \\
\hline $\begin{array}{l}\text { Ephedrine, methylephedrine, } \\
\text { pseudoephedrine }\end{array}$ & $\begin{array}{l}\text { Nasal application is } \\
\text { permitted }\end{array}$ & $\begin{array}{l}\text { Ephedrine and methylephedrine are } \\
\text { prohibited when its concentration in } \\
\text { urine is }>10 \mu \mathrm{g} \cdot \mathrm{mL}^{-1} \\
\text { Pseudo-ephedrine is prohibited when its } \\
\text { concentration in urine is }>150 \mu \mathrm{g} \cdot \mathrm{mL}^{-1}\end{array}$ \\
\hline \multicolumn{3}{|c|}{$\begin{array}{l}\text { \#: depends on appropriate patient selection (evidence of specific immunoglobulin E to clinical relevant allergens), } \\
\text { choice of allergen and correct dosage, pending a risk/benefit evaluation. It should be performed by, or under the } \\
\text { close supervision of, trained physicians. There is no contraindication to perform allergen immunotherapy in } \\
\text { athletes, with the precaution to avoid physical exercise just after receiving the injection [25]. }\end{array}$} \\
\hline
\end{tabular}

Inhaled corticosteroids have side-effects that should be taken into account mainly in relation to sports. Although uncommon, adrenal suppression is of particular concern. In healthy males inhaling fluticasone proprionate $440 \mu \mathrm{g}$ twice daily it has been found that exercise significantly increased circulating levels of fluticasone, as well as inducing a decrease in cortisol and adrenocorticotropin. The systemic effects of this topical treatment were demonstrated by an increase in peripheral blood leukocytes and neutrophils, as well as interleukin- 6 levels [34]. Adrenal suppression has also been showed in children on low-to-moderate doses of inhaled budesonide [35]. Despite the controversial results concerning growth retardation in children and adolescents induced by inhaled corticosteroids, this possibility should be also taken into account. Although rare, reduction in bone mineral density should be considered, especially when treating asthmatic women practicing endurance sports, as female marathon runners have been noted to be at particular risk for osteoporosis [17].

Anti-leukotrienes can also be tried as a protective strategy. Although, it should be 


\section{Educational questions}

1. Which of the following is not true regarding asthma in athletes?

a) Asthma is the most common chronic respiratory condition among Olympic athletes

b) Audible inspiratory stridor is a common physical finding

c) After ending exercise, the gradual and spontaneous improvement of respiratory symptoms is common

d) Respiratory symptoms have been shown to be poor predictors of asthma in athletes

e) Allergic rhinitis is more prevalent than in the general population but clinical presentation is frequently more subtle 2. It is false that:

a) Asthma-related deaths have been reported in athletes associated with a sporting event

a) There is a subgroup of athletes who are asymptomatic but present objective evidence of EIB

c) The prevalence of asthma in athletes is similar to the general population

d) Atopy and type of sport practiced are major risk factors for asthma in athletes

e) Athletes often record lung function values higher than the general population noted that in athletes only a few studies have been performed to assess the effect of montelukast and they have presented some divergent results. One study found no effect on symptoms or objective inflammation parameters [36], another study found evidence of EIB protection in some but not all athletes [37], while in another study an improved physical performance was observed [38]. It is probable, therefore, that these drugs are effective in some athletes with EIB, but not in all athletes [1, 39].

Unlike with $\beta_{2}$-agonists, tachyphylaxis for anti-leukotrienes and inhaled corticosteroids has never been reported [17, 39].

If control is not achieved, the next step will comprise the increase of inhaled corticosteroids dosage and/or the addition of a long-acting $\beta_{2}$-agonist to corticosteroids. Even with the potential for tachyphylaxis or partial loss of efficacy, regular use of longacting $\beta_{2}$-agonists (formoterol or salmeterol) in a combined strategy does have a role in the long-term treatment of asthma; patients receiving formoterol or salmeterol, in addition to budesonide or fluticasone, achieved asthma control 10 days earlier, as defined by increased lung function, decreased symptoms, and improved quality of life, including exercise and decreased exacerbations [1]. To prescribe a combination of both molecules in the same device may be of interest as a strategy to avoid the possibility of $\beta_{2}$-agonist isolated use.

In difficult to control EIA/EIB, combining inhaled corticosteroids, oral anti-leukotrienes and inhaled $\beta_{2}$-agonists may be beneficial [4]. If treatment fails, the diagnosis should be reconsidered.

For severe exacerbations oral corticosteroids might be necessary for short periods, although submission of a therapeutic use exemption to WADA will be then required [24].

Xanthines, calcium channel blockers, mast cell stabilisers such as cromolyn or nedocromil, and inhaled furosemide have modest attenuating effects on El-bronchoconstriction, but side-effects generally relegate these treatment classes to the side lines [1]. Anticholinergics have been considered as third-line treatments and are rarely required or suggested, but recent data renewed the interest for this drug with some endurance athletes presenting higher reversibility to inhaled ipratropium bromide than to inhaled $\beta_{2}$-agonists [13] (unpublished data).
Underlying rhinitis should be assessed and treated in patients with EIA because rhinitis enhances the severity of asthma. Controlling rhinitis could, therefore, improve asthma control. Also, reduced nasal congestion should improve sleep and thereby improve quality of life and, most likely, athletic performance [4]. Intranasal corticosteroids for nasal congestion are a good options [14]. Oral $\mathrm{H}$ 1-antihistamines are one of the first-line therapeutic options for allergic rhinitis as they attenuate the itching, sneezing and rhinorrhea; however, they might affect vigilance and reaction time in athletes. Therefore, secondgeneration non-sedating $\mathrm{H}_{1}$-antihistamines should be preferred. Anti-leukotrienes benefit both rhinitis and asthma.

Special precautions must be taken with respect to WADA rules related to medication use in sports. It is the athlete's responsibility to know the rules and to abide by them. However, as these guidelines often change, sometimes annually, and even with minor changes [13], the physicians treating subjects who are active in sports should also be up to date. Information can be assessed from WADA [24].

\section{Preventive strategies}

Prophylaxis of EIA includes not only premedication but also some interventions beyond pharmacotherapy which should be considered. These include allergen/irritant avoidance (when possible) and immunotherapy in patients with specific allergies. A mask that facilitates warming of inhaled air for exercise in cold air, and also warm-up and cool-down exercises [4] may be helpful to prevent or minimise EIB. A warmup of 10-15 min, including calisthenics with stretching exercises with an objective of reaching $50-60 \%$ of maximum heart rate, should be encouraged [1].

Comorbidities such as infections, gastrooesophageal reflux and sinusitis should be promptly addressed. Exposure to pollutants and tobacco smoke must be avoided. In light of the pathophysiology, hydration should be encouraged.

Breathing through the nose may allow cool dry air to be humidified and warmed, which reinforces the importance of rhinitis treatment and control.

Although no limitations in sport selection should arise for patients with EIA/EIB, 
symptoms may be decreased by selecting a sport based on its low asthmogenic potential [1].

\section{Conclusions}

Olympic athletes with asthma have consistently outperformed their peers [8], proving that with a careful diagnosis, adequate treatment and efficient preventive measures, they are able to perform at their very best. It is the physicians' obligation to recognise the disease and take all necessary actions so that asthma is not a limitation to reach a podium and world acknowledgment.

\section{Acknowledgements}

We would like to acknowledge K-H. Carlsen (Norwegian School of Sport Sciences and Dept of Paediatris, Rikshospitalet, both Oslo, Norway) for critical review of the manuscript.

\section{Key points}

- In athletes, asthma diagnosis is crucial because it is a prevalent condition with potential implications not only on their general health, but also on their competing performance.

- Self-reported symptoms of asthma and baseline spirometry tests are poor diagnostic predictors in athletes' asthma and either a positive bronchodilator or bronchial provocation challenges are required.

- Treatment of underlying asthma and rhinitis should follow available guidelines and, for those engaged in competition, physicians must also keep up-to-date on the latest doping regulations both from the IOC and WADA.

- If asthma treatment is not successful, reconsider the possible differential diagnoses.

\section{References}

1. Weiler J, Bonini S, Coifman R, et al. American Academy of Allergy, Asthma \& Immunology Work Group report: exercise-induced asthma. J Allergy Clin Immunol 2007; 119: 1349-1358.

2. Moreira A, Delgado L, Carlsen KH. Exercise-induced asthma: why is it so frequent in Olympic athletes? Expert Rev Respir Med 2011; 5: 1-3.

3. Haahtela T, Malmberg P, Moreira A. Mechanisms of asthma in Olympic athletes - practical implications. Allergy 2008; 63: 685-694.

4. Schwartz LB, Delgado L, Craig T, et al. Exerciseinduced hypersensitivity syndromes in recreational and competitive athletes: a PRACTALL consensus report (what the general practitioner should know about sports and allergy). Allergy 2008; 63: 953-961.

5. Adams F. The Extant Works of Aretaeus, the Cappadocian. London, The Sydenham Society, 1856.

6. Carlsen K-H, Anderson S, Bjermer L, et al. Exerciseinduced asthma, respiratory and allergic disorders in elite athletes: epidemiology, mechanisms and diagnosis: part I of the report from the Joint Task Force of the European Respiratory Society (ERS) and the European Academy of Allergy and Clinical Immunology (EAACI) in cooperation with GA ${ }^{2}$ LEN. Allergy 2008; 63: 387-403.

7. Haahtela T, Malmberg P, Moreira A. Mechanisms of asthma in Olympic athletes - practical implications. Allergy 2008; 63: 685-694.

8. Fitch K. An overview of asthma and airway hyperresponsiveness in Olympic athletes. $\mathrm{Br} J$ Sports Med 2012; 46: 413-416.

9. Amital H, Glikson M, Burstein M, et al. Clinical characteristics of unexpected death among young enlisted military personnel: results of a three-decade retrospective surveillance. Chest 2004; 126: 528-533.

10. Becker J, Rogers J, Rossini G, et al. Asthma deaths during sports: report of a 7-year experience. J Allergy Clin Immunol 2004; 113: 264-267.

11. Dickinson JW. Impact of changes in the IOC-MC asthma criteria: a British perspective. Thorax 2005; 6o: 629-632.

12. Holgate $S$, Lemanske R Jr, O'Byrne P, et al. Asthma Pathogenesis, In: Franklin Adkinson N, Holgate ST, Busse WW, et al. , eds. Middleton's Allergy: Principles and Practice. 7th Edn. Philadelphia, Mosby, 2008.

13. Carlsen $\mathrm{K}-\mathrm{H}$. The breathless adolescent asthmatic athlete. Eur Respir J 2011; 38: 713-720.

14. Silva D, Moreira A, Delgado L. Alergic rhinitis and sports. Allergic Rhinitis 2011 [in press].

15. Rundell KW, Im J, Mayers LB, et al. Self-reported symptoms and exercise-induced asthma in the elite athlete. Med Sci Sports Exerc 2001; 33: 208-213.

16. Storms W. Review of exercise-induced asthma. Med Sci Sports Exerc 2003; 35: 1464-1470.

17. Carlsen $\mathrm{KH}$, Anderson SD, Bjermer L, et al. Treatment of exercise-induced asthma, respiratory and allergic disorders in sports and the relationship to doping: Part II of the report from the Joint Task Force of European Respiratory Society (ERS) and European Academy of Allergy and Clinical Immunology (EAACI) in cooperation with GA(2) LEN. Allergy 2008; 63: 492-505.

18. Bonini M, Lapucci G, Petrelli G, et al. Predictive value of allergy and pulmonary function tests for the diagnosis of asthma in elite athletes. Allergy 2007; 62: $1166-1170$
3. Which of the

following is not considered an asthma diagnosis criterion in athletes?

a) Respiratory symptoms

b) Reversibility, defined as an FEV increase of at least $200 \mathrm{~mL}$ and $12 \%$ after inhaled $\beta_{2}$-agonist

c) A FEV 1 decrease $\geqslant 10 \%$ from baseline after eucapnic voluntary hyperpnoea d) A methacholine challenge with a $\mathrm{PD}_{20}$ $\leqslant 200 \mu \mathrm{g}$ (noncumulative dose) in athletes not taking inhaled steroids

e) An FEV 1 decrease from baseline $\geqslant 15 \%$ with a provocative dose of inhaled mannitol $\leqslant 635 \mathrm{mg}$ 4. Regarding asthma treatment in athletes, it is true that:

a) Tachyphylaxis is common with inhaled steroids and antileukotrienes

b) Controller and reliever therapies should not be combined

c) The same therapeutic approach used for the general population is not suited for athletes

d) Long-acting $\beta_{2}$ agonists should not be used as monotherapy

e) Salmeterol but not formoterol can be used for asthma symptoms relieve 
19. Weiss P, Rundell KW. Imitators of exercise-induced bronchoconstriction. Allergy Asthma Clin Immunol 2009; 5 : 7.

20. Delgado L, Carlsen K-H, Larsson K. Asthma-like conditions in athletes. Eur Respir Monogr 2005; 33 $67-72$.

21. Stensrud T, Carlsen K-H. Exercise induced bronchoconstriction among athletes. Am J Respir Crit Care Med 2004; 169: A694.

22. Rundell K, Spiering B. Inspiratory stridor in elite athletes. Chest 2003; 123: 468-474.

23. Spence L, Brown WJ, Pyne DB, et al. Incidence, etiology, and symptomatology of upper respiratory illness in elite athletes. Med Sci Sports Exerc 2007; 39: 577-586.

24. World Anti-Doping Agency. www.wada-ama.org/ Date last accessed: March 13, 2012

25. Bonini S, Bonini M, Bousquet J, et al. Rhinitis and asthma in athletes: an ARIA document in collaboration with GA2LEN. Allergy 2006; 61: 681-692.

26. Global Strategy for Asthma Management and Prevention. Global Initiative for Asthma. www. ginasthma.org

27. Carlsen K-H, Røksund O, Olsholt K, et al. Overnight protection by inhaled salmeterol on exercise-induced asthma in children. Eur Respir J 1995; 8: 1852-1855.

Suggested answers
1. b.
2. c.
3. a.
4. d.

31. Bermingham M, O'Callaghan E, Dawkins I, et al. Are beta2-agonists responsible for increased mortality in heart failure? Eur J Heart Fail 2011; 13: 885-891.

32. Cates C, Cates M. Regular treatment with salmeterol for chronic asthma: serious adverse events. Cochrane Database Syst Rev 2008; 3: CDoo6363.

33. Bonini M, Permaul P, Kazani S, et al. Airway inflammation, as detected by exhaled nitric oxide, predicts loss of bronchoprotection against exerciseinduced bronchospasm (EIB) from long-acting $\beta-2$ agonists (LABAs). Am J Respir Crit Care Med 2010; 181: A3722.

34. Schwindt CD, Zaldivar F, Eliakim A, et al. Inhaled fluticasone and the hormonal and inflammatory response to brief exercise. Med Sci Sports Exerc 2010; 42: 1802-1808.

35. Priftis KN, Papadimitriou A, Gatsopoulou E, et al. The effect of inhaled budesonide on adrenal and growth suppression in asthmatic children. Eur Respir J 2006; 27: 316-320.

36. Helenius I, Lumme A, Ounap J, et al. No effect of montelukast on asthma-like symptoms in elite ice hockey players. Allergy 2004; 59: 39-44.

37. Rundell KW, Spiering BA, Baumann JM, et al. Effects of montelukast on airway narrowing from eucapnic voluntary hyperventilation and cold air exercise. $\mathrm{Br} J$ Sports Med 2005; 39: 232-236.

38. Steinshamn S, Sandsund M, Sue-Chu M, et al. Effects of montelukast on physical performance and exercise economy in adult asthmatics with exercise-induced bronchoconstriction. Scand J Med Sci Sports 2002; 12: $211-217$.

39. de Benedictis F, del Giudice M, Forenza N, et al. Lack of tolerance to the protective effect of montelukast in exercise-induced bronchoconstriction in children. Eur Respir J 2006; 28: 291-295. 